\title{
The Appraisal of Commitment in Organizational Environments- Differentiating Organizational Commitment from Employee Satisfaction
}

\author{
PhD Cand. Radu Florea
}

\section{Abstract}

In order to acquire (and maintain) a high degree of commitment of a company's staff certain conditions must be met both general - that are valid for most organizations focused on profit - and specific - depending on the particularities of each company. Commitment is very relevant in calibrating the business strategy of companies in order to develop employees but also as a central objective for change management. At a general level, building commitment is conditioned on communication with employees on effective leadership, a high degree of satisfaction and a low degree of resistance to change. Change management theorists suggest that any kind of change - both planned and critical incident related- will have negative implications on organizational commitment. Becker considers communication as one of the main factors that affect commitment, important in the growth and continuation. Communication also has implications for organizational culture calibration, transmission of messages via multiple channels and is affected by several factors including commitment (Keyton, 2010). The main difference between commitment and satisfaction is strongly related to the emotional and affective study dimensions of Meyer and Allen's model on commitment (Keyton, 2010); although satisfaction can generate certain reactions from employees, it has a wide range of meanings from which results can be reported. Commitment may have different affective values because of the implications that it generates and because of their complexity. Accuracy is the most important feature as it helps in measuring commitment and maintaining a high degree of objectivity in data interpretation. Measuring attitudes in social sciences is a subject often problematic because the instruments used do not meet the criteria of validity - do not measure what needs to be measured. Therefore, the measurements may be inaccurate without the use of an appropriate methodology for identifying the exact coefficients of the survey indicators.

\section{Introduction}

Commitment is a concept consisting of several distinct dimensions; understanding why people feel this kind of closeness to the organization in which they work depends on a variety of factors. Companies may recognize and reward employees individually or as teams. A recognition which is given individually, directly from the management will be -even if involuntarily in some cases- valued higher by employees. Increasing the level of commitment of the management team and employees depends on a number of factors that must be implemented in a fair way in order to avoid conflicts. There is a wide range of strategies to enhance commitment; their application lies in the degree of adaptability for each distinct organization. Reporting a growth strategy of commitment that gives results in a company can just as easily not change anything in another one. Thus, due to its diversity commitment can be studied, understood and valued by reference to changes in organizations and by observing the valences that it may have.

Without a certain degree of commitment, adherence to organizational culture, understanding and accepting the values that are promoted by the organization, employees cannot perform in an optimal manner; for employees, a sense of belonging to the organization is as important as the technical skills necessary for occupying their positions. To have a high degree of commitment to the company is not necessarily desirable if the company is going through a major process of organizational change. If employees show a high degree of attachment to the old procedures in the company, the transition to a new operating model - different at all operational levels- may be met with major resistance at all levels of the company. In the case of an impending major change in the company, a high level of satisfaction is sought as being desirable from employees, because job satisfaction does not have significant implications at emotional level for company personnel. Even though the difference between employee satisfaction and commitment is defined as being significant for them to be studied as different aspect of an organization's culture, most companies do not have a clear view on the degree in which the first can generate pragmatic benefits, while the other can generate long term loyalty and consolidate an organization's position as a top employer on the market. 


\section{Theoretical perspectives on commitment and satisfaction within organizational environments}

Organizational commitment can be understood as a state of emotional and social attachment that an employee may feel towards the company in which he works. In order for a person to feel a sense of commitment towards the organization, his values must be in alignment with the ones that the company promotes. The concept of organizational commitment dates back to the early ' 50 s when theorists like Becker, Carper, Blumer and Hartman discussed the possibility of improving a company's performance by enhancing the levels of commitment which employees feel towards the companies in which they work (Singh, 2008). Before the

Introduction of commitment as a factor of development in organizational environments it was used in encompassing behavioral features, mainly in social science research. According to Hartman (1953), in order for an employee to have a positive perception of the company in which he works firstly there is a need to relate positively with company management. From a cultural perspective Hartman refers to the fact that in order for an organization to obtain commitment from its employees there needs to be a clear understanding of the company's mission, vision and values. In this case, considering the fact that a company's culture is promoted firstly by the management team, employees need to relate positively at an interpersonal level with the company management for them to have a high level of commitment to the company.

In 1953 Blumer introduced the term "communion" (Singh, 2008) to define the sense of belonging that employees may have towards the company. The term "communion" as seen by Blumer is defined by a high degree of cohesion at team levels showing a common organizational objective to which all members of the company can relate to (Singh, 2008). Commitment as a general paradigm in the study of organizations was founded by Becker and Carper (1956) - the first theorists who have developed empirical research - noting that motivation and employee satisfaction were not studied by a clear methodology and thus could not be accurately diagnosed. Employees with a high degree of commitment to their work were believed to have an increased interest not only to their work but also to their professional development. According to Becker's empirical studies commitment to an organization is believed to be in direct correlation to the degree in which each employee is interested in his own professional career path, and the way in which he can also benefit from the organization - from a point of view that mainly concerns learning and development of his own professional capacities. Becker (1960) perceived commitment as a characteristic attributed exclusively to professional interest that employees manifest. According to classical theories, the role of the organization in obtaining commitment refers largely to the ability to create stimulating working conditions for their employees (Singh, 2008). These perspectives were the foundation of the modern concept of organizational commitment, considered today as one of the most important elements necessary for obtaining organizational efficiency.

Secondary dimensions of commitment and work engagement identified later in the development of the concept as a study discipline concerned loyalty of employees to their organization, employee motivation and satisfaction. They began to be studied in order to establish a clear pattern of understanding of the ways of acquiring and maintaining organizational commitment at all levels of a company (Klein, 2009). In the early 1970s H. S. Becker introduced the concept of "loyalty" in the study of organizational commitment, as a factor of reference for developing and maintaining employee commitment (Klein, 2009). Becker defined employee loyalty based on past interactions that the two entities (employee and employer) had, interactions that can set a positive framework of interactions. More broadly, the loyalty concept to which Becker's theory refers to is a predetermined pattern to predict future interrelationships, based on past actions. Employees will have an increased tendency to be loyal - and to have a high degree of commitment to the employer - if the or rewarded their contribution to achieving the main company objectives. If employees will be convinced that the company offers a job that is in accordance to the way in which they perceive their own professional status, they will be loyal to the company and will do everything possible to contribute to achieving positive results for the organization.

The main theoretical model for the definition of employee satisfaction was introduced in the paradigms of social science by Herzberg (1979). Herzberg's theory states that there is a clear need of differentiation between factors that can generate employee satisfaction in hygiene factors and motivation factors. Segmenting the concept of employee satisfaction in two focus points was maintained during in the development of organizational theories due to its actuality that remained constant throughout the years. The Herzberg model was first introduced in 1959 and aimed at evaluating the theoretical concepts of satisfaction and dissatisfaction of employees by measuring them through specific indicators. (Stello, 2009). Herzberg's theory was based on studies on several organizations activating in the industrial production sector. The study conducted by Herzberg is based on a hypothesis which states that the factors that generate employee satisfaction and those that 
generate dissatisfaction will be - in most cases- different (Stello, 2009). In other words, the absence of factors that generate employee satisfaction do not to create conditions of dissatisfaction; if hygiene conditions are met, the elements that generate motivation for company personnel will create a context suitable for obtaining employee satisfaction but if hygiene conditions are not met, company employees are in a dissatisfaction state in which motivation cannot be developed.

Based on the critical incidents theory, Herzberg's study was conducted on 203 employees working in industrial production companies. The majority of the sample was made up of accountants and engineers. Respondents were questioned on issues that they considered important regarding the company culture, the working conditions, the relationship they have with their direct supervisors, also being asked to give concrete example of situations that can validate their viewpoint on the matters. Based on the deployed interviews Herzberg found that some employees have a very high degree of commitment but also that others feel very frustrated regarding their job, even though they work in the same company on similar positions and had similar financial rewards. In this initial phase of differentiation it can be stated that although all employees had a high degree of satisfaction, some of them didn't have feel committed to the company. Even if commitment is related to motivation it needs to be studied from a different perspective than job satisfaction, due to the fact that it does not depend on hygiene factors -which are presumed to be existent at a sufficient level if employees have remained for a long period of time in the organization- but only on internal motivation and dedication to their work and to the company.

A more detailed perspective on the differentiation between commitment and satisfaction is offered by Rehman (2013) who states that employee satisfaction towards their job and the company can be defined as a general opinion - positive or negative- to the nature of their work in the given organizational context. Luthans (2005) considers job satisfaction as a pragmatic view on the way in which a specific job at a specific company can or cannot create benefits for its employees; Luthans considers that job satisfaction - as opposed to employee commitment towards the company- does not have any emotional implications for employees. Loyalty towards the company can only be achieved if employees identify themselves with the company's vision, mission and values, aspects which are related to organizational commitment.

\section{Meyer \& Allen's model on commitment}

Meyer and Allen discuss employee commitment to companies from three distinct components (Meyer \& Allen, 1991):

- Affective commitment (emotional)

- Commitment based on continuity- based on the time an employee has worked within the company

- Normative commitment: the sense of obligation to remain in the company

Affective commitment refers to the organizational climate, and the way in which it can influence the emotional perception of the organization's members. The affective dimension of commitment can be found in aspects such as communication, relationships in general or the perception of pressure coming from the management team. "Affective commitment refers to the employee's emotional attachment and involvement in the organization; employees with a strong emotional commitment continue to remain in the organization because they want to, not because they need to. "(Meyer \&Allen, 1991). Commitment based on continuity refers to the employee's awareness of the costs they would have if they were to leave the organization. An employee whose primary connection with the organization is continuity will still remain in the company because he needs his current job. Normative commitment reflects a sense of obligation of the employee for the company; the employee feels that he should remain in the organization because of loyalty and fear of change (Meyer \& Allen, 1991).

The three concepts through which commitment was defined were not considered distinctive dimensions but interconnected parts that can be present in an organization in different degrees. Some employees can feel that they have a strong emotional bond with the organization but also a high responsibility towards it due to the fact that they have worked in the company for a very long time. Segmenting the concept of commitment in these three areas can help in diagnosing commitment levels with a higher precision. 


\section{Measurement differences between job satisfaction and organizational commitment}

The most common used instrument for assessing organizational commitment according to the model defined by Meyer and Allen (1991) is the Organizational Commitment Questionnaire developed by Porter and Smith in 1970. The questionnaire assesses the aforementioned three dimensions through indicators that are positively correlated with job satisfaction. The main difference between instruments that evaluate employee satisfaction and the OCQ is that the first deals with employee perception, and the second mainly assess emotional aspects that can lead to commitment. Although most of the instruments that assess job satisfaction correlate positively with instruments that assess commitment to the organization, the two concepts do not share common indicators in the assessment methodology.

Job satisfaction mainly relates with employee perceptions regarding their own position/job, financial compensations, relationship with supervisors, career paths, organizational climate ( Manzoor, 2011); as previously states, organizational commitment assess three distinct dimensions that have emotional implications for employees. Although from a methodological point of view both concepts may be assessed similarly a relevant difference for commitment instruments (like the $O C Q$ ) is that they need to be validated according to scientific criteria in order for it to be considered reliable; job satisfaction questions may be easily tailored according to punctual elements that are relevant for each company.

The main difference of measuring employee satisfaction and commitment relies on the framing of commitment in psychometric paradigms, whereas job satisfaction is mainly one's perception of the job and the company. Although scaling and formulation of the questions from each type of instruments are similar, the need for validation of instruments that assess commitment in comparisons with instruments that assess satisfaction that don't have such a requirement is the main difference in measurement of the two aspects.

\section{The role of commitment in organizational change}

One of the directions in contemporary research of organizational commitment is the evolutionary description of the level of commitment in an organization that is currently undergoing a change process (Pittinsky \& Shih, 2005). By measuring commitment in different stages of change a forecast can be defined regarding the success of implementing change and the degree in which resistance from employees can be surpassed. The research conducted by Shih and Pittinsky was deployed in an organization undergoing a process of growth in three different stages - 36 months away from each moment of application of the test battery- using scales introduced by Meyer and Allen discussed previously in this paper. By the successive application of the research instruments it was seen that as the organization grew employee commitment had decreased. The explanation given by Pittinsky and Shih was that employees have developed "a retrospective commitment" (Pittinsky \& Shih, 2005). By defining retrospective commitment as a descriptive sub-scale of commitment appraisal in organizations undergoing a change process - in this case based on structured development- was generated through a detailed analysis of the three dimensions developed by Meyer and Allen, with particular reference to the affective dimension; because employees were so emotionally committed to the organization as a static entity, the development process was perceived as problematic by them, and thus it was met with a high degree of resistance. In other words, employees who feel a high degree of identification with the values of the organization and working methods in a particular moment will develop a strong degree of commitment to the organization based on the vision, mission, and values it may have at a specific moment.

The fact that the organization is developing and improving its working patterns will not be positively perceived by employees who remain committed to an organizational culture different from the current one. Being involved at an emotional level due to issues that are no longer present in the same form lowers organization commitment and affects the organization as a whole. In this regard, commitment can be retrospectively defined as "employee adherence to a static point where the organization is at a given time" (Pittinsky \& Shih, 2005).

\section{Conclusions}

The measurement of attitudes in social sciences -and especially in organizational environments - is a sensitive matter due to the fact that the instruments that are used often do not meet the required validity - they do not measure what they imply they are measuring. Therefore, although measurements may be considerate accurate, in the absence of using a precise methodology for validating commitment instruments and for tailoring job satisfaction instruments on the company needs, 
organizational commitment cannot be diagnosed with high precision. Perspectives on measuring organizational commitment may include other dimensions such as employee perception on top management, on the external customers, on supervisors, team cooperation and working with other departments (Meyer and Allen, 2004). Therefore, differentiating commitment and satisfaction can be viewed as mandatory in a complex process of organizational culture diagnosis.

\section{References}

Kane, Katherine, 2005, Managing change to reduce resistance, Harvard Bussiness School Publishing Corporation, Boston Massachussets

Keytonn, Joan., 2010, Communication and organizational culture- a key to understanding work experiences, Sage Publications Inc., Thousand Oaks, California.

Klein, Howard J., 2009, Commitment in Organizations: Accumulated Wisdom and New Directions, Routledge Taylor \& Francis Group

Manzoor, M. U., Usman, M., Naseem, M. A., \& Shafiq, M. M. (2011). A Study of Job Stress and Job Satisfaction among Universities Faculty in Lahore, Pakistan Global Journal of Management and Business Research, 11(9):1 September 2011.

McFarlane, Shore, Martin, Harry, 1989, Job satisfaction and organizational commitment in relation to work performance and turnover intentions, Human Relatios, Vol. 42, $\mathrm{Nr} 7$

Meyer, J. \& Allen, N. (1997). Commitment in the Workplace, Sage: Thousand Oaks.

Meyer, J. P. Allen, N. J. (1991). "A three-component conceptualization of organizational commitment". Human Resource Management Review 1

Meyer, J. P., \& Herscovitch, L. (2001),Commitment in the workplace:Toward a general model, Human Resource Management Review, 11, 299-326.

Meyer, J. P., Allen, N. J., \& Smith, C., (1993). Commitment to organizations and occupations Extension and test of a threecomponent conceptualization, Journal of Applied Psychology, 78, 538-551.

Pittinsky, Todd, Shih, Margaret, Glancing Back: Recalling Organizational Commitment in a Growing Organization, John F. Kennedy School of Government, Harvard University

Stello, Christina, 2009 Herzberg's Two-Factor Theory of Job Satisfaction: An Integrative Literature Review, Department of Organizational Leadership, Policy, and Development College of Education and Human Development University of Minnesota 